\title{
ACETYLCHOLINE IN CATARACT SURGERY*
}

\author{
BY \\ R. D. HARLEY AND J. E. MISHLER \\ Atlantic City, New Jersey
}

Although the use of acetylcholine as a miotic agent in ophthalmic surgery is not new, it has not been widely used in the United States nor has it been readily available. Amsler and Verrey (1949) recorded the rapid miotic effect of acetylcholine instilled into the anterior chamber and suggested its use as a possible therapeutic agent after cataract extraction.

Acetylcholine acts directly on the motor end-plate of the sphincter muscle of the pupil to effect pupillary constriction. The activation of structures supplied by post-ganglionic fibres of the parasympathetic nervous system mediated by acetylcholine (parasympatheticomimetic action) is well known.

At the Barraquer Institute in Barcelona, where it has been used extensively, acetylcholine was being introduced into the anterior chamber as a routine measure after cataract extraction during the 1962 congress. Schimek (1961) has observed that rapid miosis permits prompt protection of the vitreous face after cataract extraction. Miosis also facilitates the addition of post-placed corneo-scleral sutures by reducing the hazard of iris incarceration by the sutures. Barraquer (1964) reported on a small series in which acetylcholine was used in the anterior chamber after cataract extraction to determine an effective concentration of the drug which was at the same time harmless to the anterior chamber structures. He stated that the $1: 100$ concentration was the most reliable and dependable for miosis but the series was too limited to be conclusive.

In certain ophthalmic surgical procedures such as cataract extraction or keratoplasty the immediate constriction of the intact pupil is a distinct advantage. In order to determine the most effective strength of acetylcholine for using in the anterior chamber two series were performed using the same premedication and technique with a total of 106 cataract extractions (Harley and Mishler, 1964). Various concentrations of acetylcholine from $1: 1000$ to $1: 100$ were injected into the anterior chamber and the pupillary size was measured one minute later. The corneas and anterior chambers have undergone careful scrutiny for any immediate or long-term changes.

The results are fully tabulated and include brief mention of some experimental observations (Tables I and II, overleaf).

\section{Premedication}

All the patients in this series had the same pre-operative medication, the dosage being adjusted according to age. Usually the patients received sodium pentobarbital (Nembutal) $100 \mathrm{mg}$. the evening before surgery, and $100 \mathrm{mg}$. 4 hours and 1 hour before operation.

* Received for publication March 30, 1965.

† Miochol brand of acetylcholine (Smith, Miller, and Patch). 
TABLE I

Results in 45 Cases-Preliminary Group

\begin{tabular}{|c|c|c|}
\hline Case & $\begin{array}{l}\text { Pupillary Diameter (in mm.) } \\
\text { after Intracapsular Extraction }\end{array}$ & $\begin{array}{l}\text { Pupillary Diameter (in mm.) } \\
\text { after Instillation of Acetylcholine }\end{array}$ \\
\hline \multicolumn{3}{|c|}{ Acetylcholine $1: 1000,7$ cases } \\
\hline $\begin{array}{l}1 \\
2 \\
3 \\
4 \\
5 \\
6 \\
7\end{array}$ & $\begin{array}{l}8 \times 6 \\
8 \times 6 \\
5 \times 4 \\
7 \times 6 \\
8 \times 7 \\
7 \times 7 \\
7 \times 6\end{array}$ & $\begin{aligned} 5 & \times 4 \\
4 \frac{1}{2} & \times 3 \frac{1}{2} \\
3 \frac{1}{2} & \times 2 \frac{1}{2} \\
4 & \times 3 \\
7 & \times 6 \\
5 \frac{1}{2} & \times 4 \text { (vitreous loss) } \\
4 & \times 3 \frac{1}{2}\end{aligned}$ \\
\hline Average & $7 \cdot 1 \times 6$ & $4.8 \times 3.8$ \\
\hline
\end{tabular}

Acetylcholine 1 : 500, 21 cases

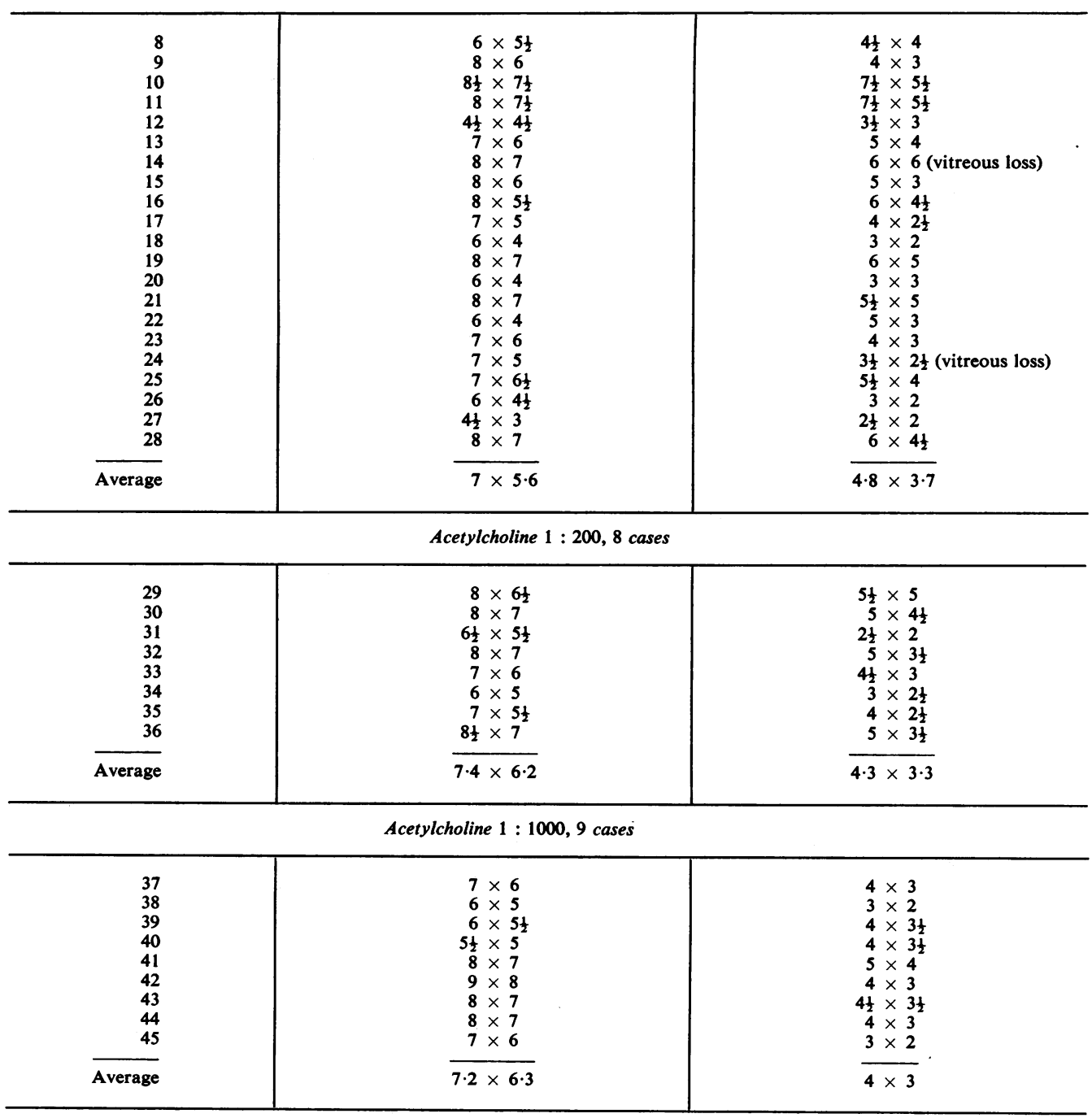


TABLE II

Results in 61 Cases-Supplemental Group

\begin{tabular}{|c|c|c|c|c|}
\hline Case & $\begin{array}{c}\text { Iris } \\
\text { Colour }\end{array}$ & $\begin{array}{c}\text { Pupillary Diameter } \\
\text { after Intracapsular } \\
\text { Extraction }\end{array}$ & $\begin{array}{l}\text { Pupillary Diameter } \\
\text { after Instillation of } \\
\text { Acetylcholine }\end{array}$ & Comment \\
\hline \multicolumn{5}{|c|}{ Acetylcholine $1: 200,30$ cases } \\
\hline $\begin{array}{r}1 \\
2 \\
3 \\
4 \\
5 \\
6 \\
7 \\
8 \\
9 \\
10 \\
11 \\
12 \\
13 \\
14 \\
15 \\
16 \\
17 \\
18 \\
19 \\
20 \\
21 \\
22 \\
23 \\
24 \\
25 \\
26 \\
27 \\
28 \\
29 \\
30 \\
\text { Average }\end{array}$ & $\begin{array}{l}\text { Brown } \\
\text { Brown } \\
\text { Blue } \\
\text { Brown } \\
\text { Brown } \\
\text { Blue } \\
\text { Brown } \\
\text { Grey } \\
\text { Brown } \\
\text { Brown } \\
\text { Brown } \\
\text { Blue } \\
\text { Hazel } \\
\text { Brown } \\
\text { Brown } \\
\text { Blue } \\
\text { Brown } \\
\text { Brown } \\
\text { Brown } \\
\text { Grey } \\
\text { Hazel } \\
\text { Brown } \\
\text { Blue } \\
\text { Brown } \\
\text { Brown } \\
\text { Brown } \\
\text { Hazel } \\
\text { Brown } \\
\text { Blue } \\
\text { Blue }\end{array}$ & $\begin{aligned} 8 & \times 6 \frac{1}{2} \\
8 & \times 7 \\
7 & \times 5 \\
6 & \times 4 \\
8 & \times 7 \frac{1}{2} \\
6 & \times 5 \frac{1}{2} \\
8 & \times 7 \frac{1}{2} \\
4 & \times 3 \\
6 & \times 5 \\
5 & \times 4 \frac{1}{2} \\
7 & \times 6 \\
8 \frac{1}{2} & \times 7 \frac{1}{2} \\
7 & \times 6 \\
8 \frac{1}{2} & \times 7 \\
5 \frac{1}{2} & \times 4 \\
6 & \times 4 \frac{1}{2} \\
10 & \times 6 \\
6 & \times 6 \\
8 & \times 6 \\
8 & \times 8 \\
7 & \times 6 \\
7 \frac{1}{2} & \times 6 \\
6 & \times 4 \\
5 & \times 4 \frac{1}{2} \\
5 \frac{1}{2} & \times 3 \frac{1}{2} \\
6 & \times 5 \\
5 \frac{1}{2} & \times 5 \\
6 & \times 5 \\
6 & \times 5 \\
7 & \times 5 \\
6.8 & \times 5 \cdot 8\end{aligned}$ & $\begin{aligned} 6 \frac{1}{2} & \times 5 \\
6 \frac{1}{2} & \times 6 \\
5 & \times 2 \\
3 & \times 2 \\
5 & \times 4 \\
3 \frac{1}{2} & \times 2 \frac{1}{2} \\
6 & \times 5 \\
3 & \times 2 \\
3 \frac{1}{2} & \times 2 \frac{1}{2} \\
3 & \times 2 \frac{1}{2} \\
5 & \times 3 \frac{1}{2} \\
5 & \times 4 \\
5 & \times 4 \\
5 & \times 4 \\
4 & \times 3 \\
3 & \times 2 \\
4 & \times 3 \\
3 & \times 3 \\
4 & \times 3 \\
4 & \times 3 \\
4 & \times 3 \\
3 \frac{1}{2} & \times 2 \frac{1}{2} \\
2 & \times 2 \\
3 \frac{1}{2} & \times 2 \frac{1}{2} \\
4 & \times 3 \\
2 \frac{1}{2} & \times 2 \\
3 & \times 2 \frac{1}{2} \\
4 \frac{1}{2} & \times 3 \\
3 \frac{1}{2} & \times 2 \frac{1}{2} \\
4 & \times 3 \\
4 \cdot 2 & \times 3 \cdot 2\end{aligned}$ & $\begin{array}{l}\text { Alpha-chymotrypsin } \\
\text { Alpha-chymotrypsin } \\
\text { Chronic glaucoma } \\
\text { Full iridectomy } \\
\text { Alpha-chymotrypsin } \\
\text { Chronic glaucoma } \\
\text { Small liquid vitreous loss }\end{array}$ \\
\hline \multicolumn{5}{|c|}{ Acetylcholine $1: 100,31$ cases } \\
\hline $\begin{array}{r}31 \\
32 \\
33 \\
34 \\
35 \\
36 \\
37 \\
38 \\
39 \\
40 \\
41 \\
42 \\
43 \\
44 \\
45 \\
46 \\
47 \\
48 \\
49 \\
50 \\
51 \\
52 \\
53 \\
54 \\
55 \\
56 \\
57 \\
58 \\
59 \\
60 \\
61 \\
\text { Average }\end{array}$ & $\begin{array}{l}\text { Brown } \\
\text { Grey } \\
\text { Brown } \\
\text { Blue } \\
\text { Blue } \\
\text { Brown } \\
\text { Grey } \\
\text { Blue } \\
\text { Hazel } \\
\text { Brown } \\
\text { Grey } \\
\text { Hazel } \\
\text { Blue } \\
\text { Blue } \\
\text { Blue } \\
\text { Brown } \\
\text { Brown } \\
\text { Blue } \\
\text { Brown } \\
\text { Brown } \\
\text { Brown } \\
\text { Blue } \\
\text { Blue } \\
\text { Hazel } \\
\text { Brown } \\
\text { Brown } \\
\text { Hazel } \\
\text { Brown } \\
\text { Blue } \\
\text { Hazel } \\
\text { Blue }\end{array}$ & $\begin{aligned} 7 & \times 6 \frac{1}{2} \\
5 \frac{1}{2} & \times 4 \\
8 & \times 6 \\
7 & \times 6 \\
5 & \times 3 \\
5 & \times 4 \\
8 & \times 6 \\
5 & \times 4 \frac{1}{2} \\
7 & \times 6 \\
7 & \times 6 \\
6 & \times 4 \\
6 & \times 4 \\
7 & \times 6 \\
7 \frac{1}{2} & \times 6 \\
5 & \times 5 \\
6 & \times 5 \\
7 & \times 5 \\
7 & \times 7 \\
6 & \times 5 \\
6 & \times 6 \\
6 & \times 6 \\
7 & \times 6 \\
7 & \times 6 \\
8 & \times 6 \\
7 & \times 6 \\
6 & \times 5 \\
6 & \times 6 \\
6 \frac{1}{2} & \times 4 \\
5 & \times 5 \\
7 & \times 6 \\
5 & \times 4 \frac{1}{2} \\
66 & \times 5.2\end{aligned}$ & $\begin{aligned} 4 & \times 3 \\
4 & \times 3 \\
5 & \times 4 \\
4 & \times 3 \\
2 \frac{1}{2} & \times 2 \\
2 \frac{1}{2} & \times 2 \\
4 & \times 3 \\
3 & \times 3 \\
6 & \times 4 \\
4 & \times 3 \\
5 & \times 3 \frac{1}{2} \\
3 & \times 2 \\
4 & \times 2 \frac{1}{2} \\
5 \frac{1}{2} & \times 3 \\
2 & \times 2 \\
3 & \times 3 \\
5 & \times 2 \\
4 & \times 2 \frac{1}{2} \\
2 & \times 2 \\
3 & \times 2 \\
4 & \times 3 \\
3 & \times 2 \frac{1}{2} \\
5 & \times 4 \\
4 \frac{1}{2} & \times 3 \\
4 & \times 3 \\
4 & \times 2 \\
4 & \times 3 \\
4 & \times 2 \frac{1}{2} \\
4 & \times 2 \\
6 & \times 4 \\
3 & \times 2 \\
3.8 & \times 2.7\end{aligned}$ & $\begin{array}{l}\text { Small liquid vitreous loss } \\
\text { General anaesthesia } \\
\text { Alpha-chymotrypsin }\end{array}$ \\
\hline
\end{tabular}


Meperdine (Demerol) 50-100 mg. and prochlorperazine (Compazine) $10 \mathrm{mg}$. were given on call for the operating theatre. Additional meperdine was often injected at the operating table if the patient were insufficiently sedated.

Acetazolamide $500 \mathrm{mg}$. was routinely prescribed the evening before surgery and 5 per cent. homatropine was instilled into the lower cul-de-sac of the eye to be operated on. Additional mydriasis was obtained by instillation of 10 per cent. phenylephrine 15 minutes pre-operatively.

Local anaesthesia was used in all cases. Routine orders called for the instillation of proparacaine hydrochloride (Ophthetic) 0.5 per cent. topically, Xylocaine ( 2 per cent.) for lid akinesia, and 1 c.c. of 2 per cent. Xylocaine for the retrobulbar block.

\section{Technique}

The acetylcholine unit consists of the desiccated powder, in varying quantities depending on the desired strength, in a double-chambered vial separated by a compressible rubber stopper. For example, each vial of the $1: 100$ contains acetylcholine chloride $20 \mathrm{mg}$., mannitol $100 \mathrm{mg}$., and sterile water (upper chamber) $2 \mathrm{ml}$.

Since the prepared acetylcholine solution is unstable, the material is prepared just before its use by the scrub nurse. The acetylcholine is drawn into a 2-c.c. sterile dry syringe to which is attached a blunt anterior chamber irrigator.

A peripheral iridectomy is performed at the 12 o'clock position and the cataract is extracted with the erysiphake. Immediately after the intracapsular extraction, the two corneoscleral sutures pre-placed at the 10.30 and 1.30 o'clock positions are secured. Horizontal and vertical measurements of the pupil are carefully checked with the Castroviejo caliper. After extraction the pupil is frequently somewhat oval in shape, due, in part, to the method of performing the peripheral iridectomy.

The acetylcholine is injected just lateral to the tied sutures. Approximately 0.5 c.c. is injected in a small jet stream on each side; at once the anterior chamber deepens and the pupil constricts. Horizontal and vertical measurements of the pupil are taken at the end of one minute. Sterile pilocarpine ( 2 per cent. drops) is instilled at the conclusion of the operation. At the first dressing the pupil is miotic, round, and centric.

After injection of acetylcholine into the anterior chamber six additional corneo-scleral sutures are inserted, making a total of eight sutures to produce a water-tight closure.

\section{Experimental Data}

Two dogs weighing approximately $12 \mathrm{~kg}$. were anaesthetized with pentothal sodium injected intravenously. By means of an 18-gauge needle inserted directly into the anterior chamber aqueous could be removed and replaced with varying strengths of acetylcholine. Pilocarpine nitrate 6 per cent. was used as a control.

In dog No. 1 instillation of pilocarpine nitrate 6 per cent. in the right eye affected no demonstrable miotic action at the end of 2 minutes. Instillation of 1 c.c. of acetylcholine $1: 100$ in the left eye resulted in a prompt response in the size of the pupil from an original diameter of $11 \frac{1}{2} \mathrm{~mm}$. to a reduced size of $8 \frac{1}{2} \mathrm{~mm}$. at the end of 2 minutes.

In $\operatorname{dog}$ No. 2 the aqueous was evacuated from the right eye and the pupil was then found to measure $10 \mathrm{~mm}$. in diameter. Instillation of 1 c.c. of acetylcholine $1: 100$ reduced the pupillary diameter from $10 \mathrm{~mm}$. to $8 \frac{1}{2} \mathrm{~mm}$. In the left eye a 2 per cent. acetylcholine solution reduced the pupillary size $3 \mathrm{~mm}$. in diameter in 2 minutes, but a mild cellular response resulted. A 4 per cent. acetylcholine solution resulted in a prompt reduction in pupillary size, but the aqueous immediately became cloudy, suggesting a severe iritic irritation. A solution with this concentration of drug was quite obviously unsuitable for clinical purposes. 
Results

Acetylcholine in dilutions of $1: 1000,1: 500,1: 200$, and $1: 100$ promptly induced a miotic effect when injected into the anterior chamber. The miosis varied to a limited degree with the concentration of drug introduced into the iris tissue. There were some individual variations with identical concentrations of acetylcholine.

A series of 106 cases were observed for miotic effect, signs of irritation, healing, and general post-operative reaction. The table of results and our clinical impression suggest that the $1: 200$ and $1: 100$ dilutions were most effective. Dilutions of $1: 50$ and $1: 25$ evoked signs of iritic irritation in the dogs' eyes. The miotic effect of acetylcholine does not last long and must be supplemented by a miotic such as pilocarpine applied topically at the conclusion of the surgery. The use of alphachymotrypsin appeared to have no inhibiting effect on acetylcholine.

Acetylcholine appeared to stimulate the human iris to an equal degree irrespective of the colour. There was no consistent difference in the degree of miosis when different coloured irides were stimulated with acetylcholine. From the experimental animal we suspected that the brown iris might react with less vigour than the blue, but this observation did not appear to be true with the human iris.

The jet stream of normal saline without the drug had a measurable miotic effect which varied between 1 and $2 \mathrm{~mm}$.

The best miosis was produced in those eyes where the iris seemed to "float" on the hyaloid membrane after lens extraction. The poorest response from acetylcholine occurred in those cases where the iris was displaced into the wound margin after lens extraction.

No infections or iritic irritations were encountered in the human eyes. A small amount of liquid vitreous presented at the wound lips in five cases. Aspiration of vitreous from the wound margins, combined with a gentle stream of acetylcholine irrigated in the direction of the pupillary centre, resulted in a well-positioned round pupil in each instance.

\section{Conclusions}

Acetylcholine irrigated into the anterior chamber after cataract extraction induced a prompt effective miosis which protected the vitreous face and facilitated the placement of corneal sutures by reducing the hazard of incarcerating iris.

Miosis induced by acetylcholine is not long maintained and must be augmented by a longer acting miotic. Dilutions of acetylcholine in 1:200 and 1:100 were most effective in the production of miosis.

Acetylcholine was not affected by the previous use of alpha-chymotrypsin and had approximately the same miotic effect irrespective of iris colour.

During the period acetylcholine was used in the above concentrations there were no infections, and no signs of iritic irritation or of interference with wound healing.

Acetylcholine has been observed to be a valuable adjunct in corneal grafting.

\section{REFERENCES}

Amsler, M., and Verrey, F. (1949). Ann. Oculist. (Paris), 182, 936.

BarraQuer, M. J. I. (1964). Amer. J. Ophthal., 57, 406.

HARLEY, R. D., and Mishler, J. E. (1964). Ibid., 57, 817.

SCHIMEK, R. A. (1961). An. Inst. Barraquer, 2, 687. 